\title{
Income And Spending Behaviors In Relation To Social Life And Living Conditions Among Kenyan University Students.
}

\author{
Leonard K. Ali. Alice A. Anika \\ Mathematics and Computer Science departmentPwani University - P.O. Box 195 Kilifi, Kenya \\ Educational psychology and Special Needs DepartmentPwani University - P.O. Box 195 Kilifi, Kenya.
}

\begin{abstract}
The purpose of this study was to investigate the income and spending behaviors of university students, Kilifi County Kenya. in relation to social life and living conditions. Across sectional survey design About 360 Students were randomly selected from the university's schools using stratified and proportionate random sampling technique. The results revealed that majority of the female students spent almost twice the amount they receive from different sources compared to males. The average income of a male student was found as Ksh 5538.50 compared to that of a female student (Ksh 6678.60). The average expenditure of female students was Kshs.10619.30. The amount paid by students on rent ranged from Ksh 2500 to Ksh 30,000, with an average of Ksh 9064 and a standard deviation of Ksh 6301.In general students felt that residing in the university was more secure (average $=7.42$ (1.7)), more convenient $(7.04(1.8)$ ) and more hygienic for the learning environment than outside the university. On the other hand, students felt that staying outside the university was more private than residing within the university.
\end{abstract}

Key words; Income and expenditure, Spending behaviors, Social life, Living conditions, Kenyan Public University students.

\section{INTRODUCTION}

The number of students in Kenya's universities has been on the rise by $28 \%$ in 2014 compared to 2013. But, contrary to expectations, the government has cut funding by $6 \%$ for the upcoming fiscal year, adjusting its higher education spending to US\$588 million compared to the US\$627.2 million allotted in 2014/15. (IECF Monitor, 2015 Report). This deficit makes it difficult for universities to cater for the growing numbers of students taking science courses and other university services such as bursaries. This makes the universities, parents and students to look for other alternative sources to support their endeavor to attain university education. This precarious situation is most difficult for both parents and students. Many students are forced to defer their studies and some completely drop out. Akoojee and Nkomo, (2007) asserted that with regard to the implications of university expansion and social policy, equity and access, critical to the perception of fairer societies, social change and national development, University's education however has become very costly in recent times yet students are in the transition period of their lives from secondary to tertiary level of education. This is the stage where the young adults needs complete support, direction and guidance for successful transition to the developmental tasks in the next stage of development. In today's world, much has changed, and individuals make their transitions in a highly competitive market driven world which is highly characterized by competition and individualism.

Therefore in this context presented, students form friendships, new living arrangements and social patterns to adopt in such environments in search for knowledge. The university therefore brings challenges such as managing lifestyle choices, the development of self care skills, personal choices, decision making, individual responsibilities and personal independence (Parker et al, 2002). Students encounter and must adjust to new demands in social, academic and financial domains. According to Abdullah, Elias, Mahyuddin \& Uli, (2009) students who are able to adjust well in campus are found to display greater academic performance compared to those who have difficulty to adjust to university life and this state is worsened with the student's financial management ability. Additionally, Bling (2003) asserts that, student's transition period from high school to university is known to shake their social security, physical comfort and ability to enjoy gratifying activities among themselves, especially the first year students. This was further a affirmed by Wangeri, Mutwaleli and Kimani, (2012) that transiting from high school to tertiary level of education can be a stressful social and psychological event to students. It is therefore important to engage with students in relation to their health in order to support successful university experiences, linked to both academic performance and student retention (Pascarella et al, 2007, DeBerard et al, 2004;).

According to Kenya Universities and Colleges Central Placement Services (KUCCPS) any student who scores $\mathrm{C}+$ and above qualifies to join the University and so due to limited government funding parents tend to seek 
admission to the university through other modes of study such as institutional based or part-time mod of studies. Universities however have had very limited facilities to match the ever growing number of students in the universities. Students have had to look for other sources of finances to cater for their needs, given the rise in the cost of living. This however has come with its own share of problems such as housing shortage which has become acute and the situation doesn't seem to have a solution in the near future. As a result, University students are found to be involved in small scale entrepreneurship, house maids, commercial sex workers, hawkers and other criminal activities which have posed a threat to the security of the country.

Recent cases of attacks in Kenya have revealed shocking information about the involvement of well educated young men who have been lured to join youth radicalization criminal groups just to earn a living. Such activities have serious repercussions in the future of this nation. Students who join the universities are forced to seek for housing off campus. Yet transition from high school to university is often known to shake social security, physical comfort and ability to enjoy gratifying activities for first year students. Bernier, Larose, \& Whipple, (2005) affirm that transiting from high school to the tertiary levels of education can be stressful social and psychological event. All over sudden, students find themselves in a very different environment away from parents, known teachers and to a new university environment with peers of high diverse cross cultural background, and in where they have to make personal decisions in all their daily activities by themselves, thus from dependency to abrupt independence with no background in personal financial expenditures. Talbert (2008) concurs that each first year student has to make decisions regarding where they sleep, what to spend, how to spend, who to socialize with among other decisions. A midst these challenges some university students have shown extremely extravagant lives. The most worrying concerns are what could be the source of the student's income for the kind of spending habits they seems to exhibit? Such trends are usually noticeable in student's life styles, manner of dressings, places of residents off campus to political aspirants funding during campaigns for their university positions. Who could be contributing heavily on the university student's decision makings? The aim of this study however, was to determine whether there is a relationship between average income and expenditure of students across gender and to determine students ratings on their privacy, security, convenience and hygiene within and off campus.

\section{Objectives of the study}

This study was guided by the following objectives specifically

1) To determine the different levels of expenditures in relation to the different sources of income among students across gender.

2)To establish students ratings on their privacy, security, convenience and hygiene within and off campus.

3) To establish whether there was any significant difference in the average income of students across gender.

\section{Statement of the problem}

University student's unmet needs often contribute to student's socio-economic ill behaviors which jeopardize their academic achievements and personal goals aspirations in life. The problem of this study was to establish whether there is a relationship between average income and expenditure of students across gender and determine student's ratings on their privacy, security, convenience and hygiene within and off campus environment as documented challenges students in this region face in their campus life experiences.

\section{METHODOLOGY}

The study adopted a cross sectional survey design. Stratified sampling technique with a random sample size of 361 using proportional allocation to university academic stratum of six schools were used as shown on Table 1 .

Table 1; Sample Frame from University's Academic Schools

\begin{tabular}{|l|l|l|}
\hline School & Number of students & Sample \\
\hline Agriculture & 981 & 62 \\
\hline Humanities & 907 & 57 \\
\hline Education & 2033 & 128 \\
\hline Health and & 419 & 26 \\
\hline Science & 747 & 47 \\
\hline Environment & 629 & 40 \\
\hline Total & $\mathbf{5 7 1 6}$ & $\mathbf{3 6 1}$ \\
\hline
\end{tabular}

To achieve the desired precision for the survey estimates, the sample size was adjusted for the anticipated response rate. This was done by selecting a larger sample based on an expected response rate estimated from similar surveys or a pilot survey on the same population. Data was analyzed using Welch two sample T test 
techniques to see whether there was any significant difference in the average income of students across gender. Kolmogorov-smirnov test was also used to test whether the data met the normality assumptions.

\section{RESULTS AND DISCUSSIONS}

Demographic characteristics revealed the following outcome from the participants, $62 \%$ of the respondents were male while $38 \%$ were female.54\% of the sampled students were on KUCCPS while $46 \%$ were self-sponsored programmes.72\% of the respondents were under KUCCPS while $28 \%$ w Students were also classified according to whether they were KUCCPS students or Self sponsored, or Residents or nonresidentsThe study sought to understand the student expenditures in relation to the different sources of income they have. The major sources of their income were parents/guardians; business, HELB, bursaries, sponsors and few had other sources like boyfriends. It was also noted that some students had more than one source of income. $55.6 \%$ of the students said they were funded by the parents and guardian, $17.7 \%$ relied on HELB, 14.4\% got bursaries and $8.9 \%$ had sponsors. Figure 1 below shows the relationship between the students income and there expenditure for males and females paneled over whether a student was a resident in the university or resides outside the university.

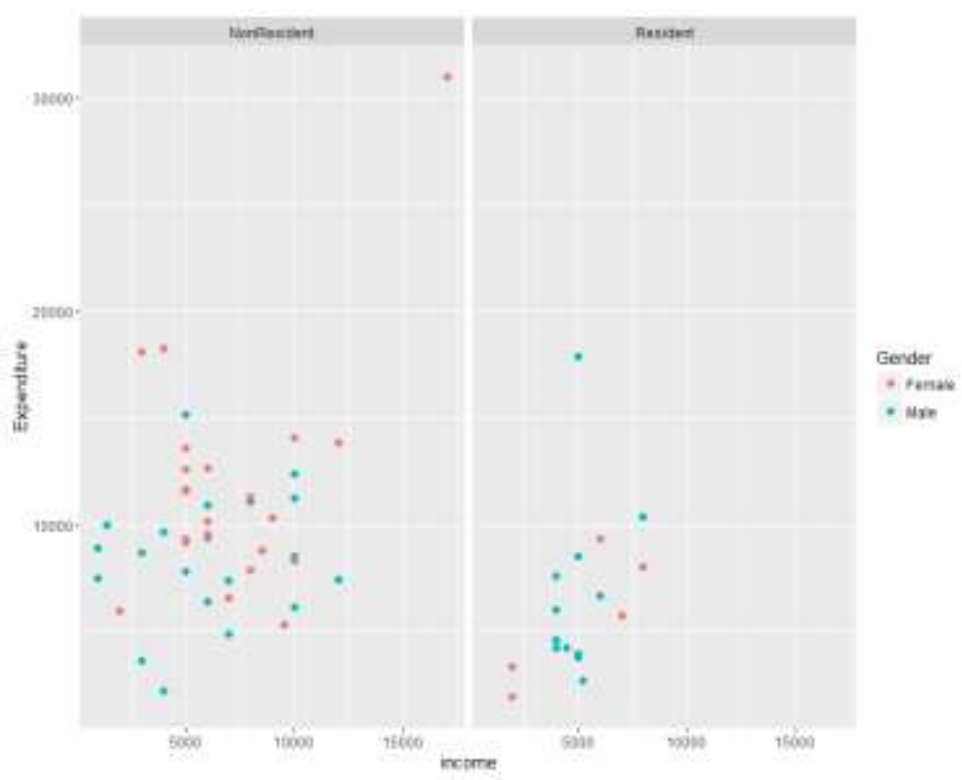

Figure 1: shows the relationship between the students income and their expenditure

From Figure 1 it can be seen that female nonresident's students have very high expenditure compared to male students. These results could be attributed to the other sources of income the female students engage themselves in compared to the male students.

Table 2; Average students expenditures across Gender

\begin{tabular}{|l|l|l|l|l|l|l|}
\hline & Entertainment & Transport & stationary & Rent & Cloth & Hair \\
\hline Male & 1027.30 & 303.00 & 179.80 & 2153.60 & 736.10 & 98.80 \\
\hline Female & 770.00 & 1132.10 & 318.90 & 1442.40 & 1491.10 & 1046.10 \\
\hline $\begin{array}{l}\text { Welch } t \text { - } \\
\text { statistic }\end{array}$ & -0.73685 & 2.3295 & 1.375 & 1.7224 & 2.2455 & 5.5386 \\
\hline$d f$ & 54.849 & 30.262 & 36.035 & 58.852 & 43.923 & 27.637 \\
\hline$p$-value & 0.4644 & 0.02669 & 0.1776 & 0.0902 & 0.02982 & 0.0000 \\
\hline $95 \%$ CI & $(-957.00$, & $(1132.10$, & $(-66.10$ & $(-$ & $(77.30-$ & $(594.70-$ \\
& $442.50)$ & 303.00 & $344.20)$ & $\begin{array}{l}115.00- \\
1537.30)\end{array}$ & $1432.70)$ & $1293.40)$ \\
\hline
\end{tabular}

From Table 2, the summary of the average student's expenditure type by gender clearly reveals that, the average income of a male student was Ksh 5538.50 compared to that of a female student of Ksh 6678.60. This is another indication revealing high expenditure among female students compared to amount they can afford. This help to support other studies views that going to college is a time when adjustment difficulties and independence in personal economic planning is crucial to every university students because in the span of human growth and development, these group of students are just on another transition stage of their lives. This is the age between 
18-24 years and those who are older are up to 3o years. At the same time, life at the university prepares students to road map to either harmful health-related behaviors or positive career and personal development. The transitions are in different folds; Maturation, exposure, knowledge acquisition and critical thinking and analytical skills of concepts. Thus, university life brings challenges such as managing lifestyle choices, the development of self care skills and personal independence (Parker et al., 2002). Students encounter and must adjust to new demands in social, academic and financial domains. It is, therefore, important to engage with students in relation to their health in order to support successful university experience, linked to both academic performance and student retention (DeBerard et al., 2004; Pascarella et al., 2007)A Welch two sample T test techniques was conducted to see whether there was any significant difference in the average income of students across gender. However, the study revealed that the difference was not statistically significant at 5\% level of significance $(\mathrm{t}=1.4667, \mathrm{p}$-value $=0.1484)$. The average expenditure of female students $($ Kshs.10619.30) however differed significantly from the male students expenditure at 5\% level of significance $(\mathrm{t}=2.4201$, $\mathrm{p}$ value $=0.01966$ ). The study also revealed that majority of students pays their rents ranging from Ksh2500 to Ksh 30,000, with an average of Ksh9064 and a standard deviation of Ksh 6301

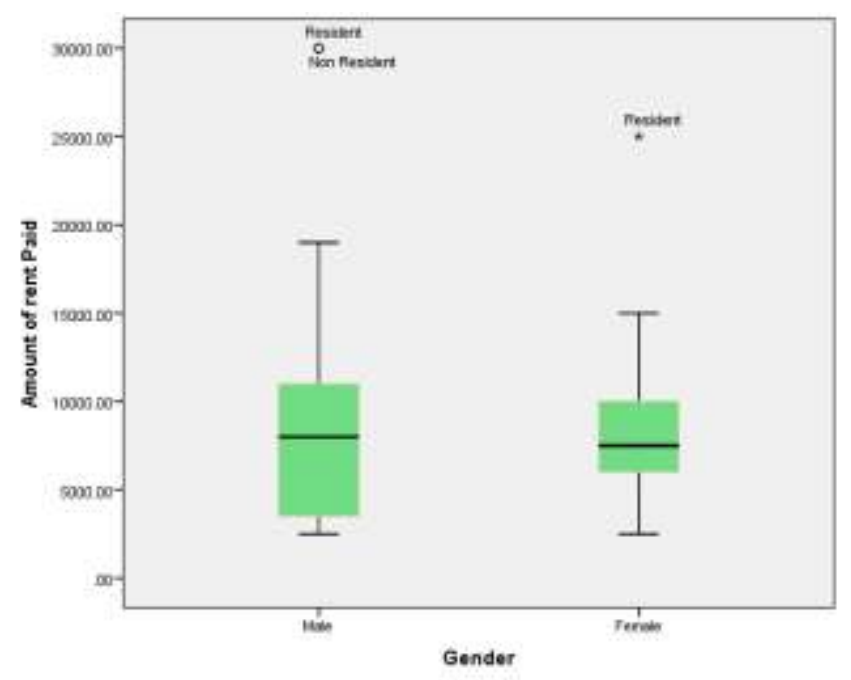

Fig 2; Distribution of students rent payment across gender.

The box plot in figure 2 shows the distribution of rent paid by gender. We observed that there was more variability in rent paid by Male students than female students. The respondents also rated privacy, security, convenience and hygiene within and off campus on a scale of 1-10 with a lower rating being indicative of a bad situation. The data was tested for normality assumptions using the Kolmogorov-smirnov test. The T-test was then used to check whether there were any significant differences in the rating for students who were residing within the university compared to those outside the university. The results are as shown in Table 3.

Table 3: Average Rating, Standard Deviation and the Standard Error of the mean

\begin{tabular}{|l|l|l|l|l|l|}
\hline$\cdot$ & Mean & Sd & $\begin{array}{l}\text { Std Error } \\
\text { of the Mean }\end{array}$ & $\mathrm{t}$ & $\mathrm{P}$ value \\
\hline Campus privacy & 4.12 & 2.3874 & 0.3376 & 6.045 & 0.000 \\
\hline Off campus privacy & 7.04 & 2.2494 & 0.3181 & & \\
\hline Campus security & 7.42 & 1.7623 & 0.2492 & 8.898 & 0.000 \\
\hline Off campus security & 4.08 & 2.4482 & 0.3462 & & \\
\hline Campus Convenience & 7.02 & 1.7735 & 0.2534 & 7.107 & 0.000 \\
\hline Off Campus Convenience & 4.20 & 1.8594 & 0.2656 & & \\
\hline Campus hygiene & 5.56 & 2.1868 & 0.3093 & 0.695 & 0.490 \\
\hline Off campus hygiene & 5.20 & 2.1946 & 0.3104 & & \\
\hline
\end{tabular}

The results from Table 3 revealed the average rating, standard deviation and the standard error of the mean. In general students felt that residing in the university was more secure $(\mathrm{t}=8.898, \mathrm{p}=0.000)$ and more convenient $(\mathrm{t}=7.107, \mathrm{P}=0.000)$.

There were no significant difference in the hygiene conditions within the university and outside the university $(\mathrm{t}$ $=0.695, \mathrm{p}=0.490)$. 
Students felt that staying outside the university was more private than residing within the university. A student residing outside the university would take 12 minutes on average to walk to campus for a lecture which enhanced student's health upkeep. All the respondents in the study sighted water problem as acute weather in or off campus.Study also revealed that theft cases within and outside the university were also on the rise. The research found out that average student's expenditure was higher than their income. Male students on average spent less than their female counterparts. Highest percentage of student income was spent on food followed by rent then entertainments. Stationery took up the lowest proportion of student income. Such study results supports Fish (2010) findings where by Fish insisted that to build an exclusive on-campus student housing, the right understanding of students different wants and needs for their house is very attentive. By creating a livinglearning environment that promote collaboration, nourished cohesion, and friendly community in the campus area, it helps to develop social skills which help students become mature adults and intern it prepares them for their future life as asserted by (Cleave, 1996; Fish, 2010). Likewise, Chan et al. (2011), Nugent (2012), and Muslim et al, (2013) reckoned that the focus of building on campus student housing must be deliberately thoughtful to stimulate satisfactory living condition and positively affect people-environment congruity to grant for the academic success and students' self development. It is important to take not that, failure to provide Fish, (2010) model of students housing model environment, this study reveals that despite that model provision, they perceive housing outside the campus as more private than within the campus. This helps to justify the attainment of this study objective by validating the different levels of expenditures among students in relation to different sources of income across gender and establishing student's ratings on their privacy, security, convenience and hygiene within and off campus. Thus student's expenditure behaviors are webbed up in a combination of intellectual and self-development gains which are embedded in young adult's life span.

\section{CONCLUSION AND RECOMMENDATION}

Each section of the findings gives valuable insight on the student experience, and suggests the need for continued work on promoting health and wellbeing. The demand for higher education is growing at an incredible pace due to pace of innovative, creative development among the youth. Great strides must be taken to nature, tap and mentor talents and intelligence for the development of mankind and enhancement of better life. Such fountain of thought can only be built in institutions of higher learning where provision of healthy quality learning space and integrity to overcome student's socio-economic milieu at individual, community and national level are enhanced. Several priorities can be readily identified:

- The need to strengthen dean of student's office to cater for support for students needs in such socio-economic hurdles to promote conducive learning environment.

- The University should strive to build more hostels in campus to boost student's safety, conveniences and also to help boost cross cultural aspects of developments for national integration and cohesion.

- Strengthen student's financial support system by introducing students work programme, awareness of various bodies to access scholarships.

- Further trainings on life skills

\section{CONCLUSION}

Students spending behaviors in relation to social life and living conditions helps to identify a profile of student's needs, spending habits and perceptions of the university experiences. The campus is an important setting for promoting individual personality. Study suggests need to scale up enhance economic support for students.

\section{REFERENCES}

[1] Abdullah,M. C., Elias, H., Mahyuddin, R., Uli, J. (2009). Adjustment amongst first year students in a Malysian university: European Journal of Social Sciences - $\quad$ Volume 8, Number 3

[2] Akoojee, S. and Nkomo, M., (2007), 'Access and Quality in South African Higher Education: The Twin Challenges of Transformation', South African Journal of Higher Education, 21, pp. 65-68.

[3] Bernier, A., Larose, S., \& Whipple, N. (2005). Leaving home for college:

[4] A potentially stressful event for adolescents with preoccupied attachment patterns.

[5] Attachment and Human Development, 7(2), 171-185

[6] Chan, J., Dubois, S., Fahey, R., \& Josephs, S. (2011). Evaluating Student Housing in London. MA: BSc Dissertation, Worcester Polytechnic Institute, Worcester.

[7] Cleave, S. L. (1996). Residence Retention: Reasons Student Choose to Return or Not to Return. College Student Journal, 30, 187- 199.

[8] DeBerard,M.S.,Spielmans,G. I ,\&Julka, D.C (2004). Predictors of academic achievement and retention among college freshman: A longitudinal study. College Student Journal,38,66-81

[9] Fish, C. T. (2010). The Case for Traditional On-Campus Housing. School Construction News - Design + Construction + Operations, 16(2), 12-13. 
[10] Muslim, M. H., Karim, H. A., Abdullah, I. C., \& Ahmad, P. (2013). Students' Perception of Residential Satisfaction in the Level of Off-Campus Environment

[11] Procedia - Social and Behavioral Sciences, 105, 684-696.

[12] Nugent, J. (2012).Solving the Puzzle of Residential Life. Retrieved December 12, 2012, from College Planning \& Management:

[13] http://peterli.com/cpm/archive.php?article_id=3378.

[14] Parker, J.D.A, Summerfeldt,L.J,Hogan,M.J. \&Majeski, S.(2004). Emotional intelligence and academic success: Examiningthe transition from High school to university. Personality and individual differences, 36,163-172.

[15] Pascarella, E. T., Goodman, K. M., Seifert, T. A., Tagliapietra-Nicoli, G., Park, S., \& Whitt, E. J. (2007). College student binge drinking and academic achievement: A longitudinal replication and extension. Journal of College Student

[16] Development, 48, 715-727.Parker et al., (2002).

[17] Talbert, J.E. and J. L. David, (2008), Evaluation of the Disciplinary Literacy-Professional

[18] Learning Community Initiative in Austin Independent School District: Final Report, Stanford CA: Center for Research on the Context of Teaching.

[19] Wangeri T, Kimani E and Mutweleli M, Transitional Challenges Facing University First Year Students in Kenyan Public Universities: A Case of Kenyatta University. Interdisciplinary Review Journal of Economics and Management 2, 1 (2012) 